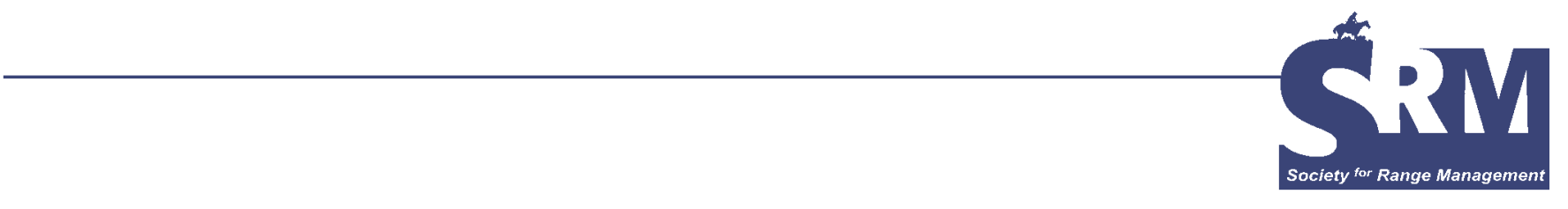

\title{
Provo Scientist Designated Forest Service "Super Scientist"
}

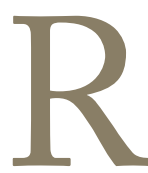

esearch geneticist Durant McArthur, from the Rocky Mountain Research Station's Shrub Sciences Laboratory in Provo, Utah, was recently named a "super scientist" by the Forest Service.

The U.S. Department of Agriculture and the Forest Service have a ceiling on the number of scientists who can be awarded the Science Technical level classification. There are only a handful of researchers across the nation with the Science Technical grade and McArthur is the only Forest Service scientist in the entire Interior West given the honor of super scientist.

McArthur has written more than 400 scientific publications - more than any other Forest Service

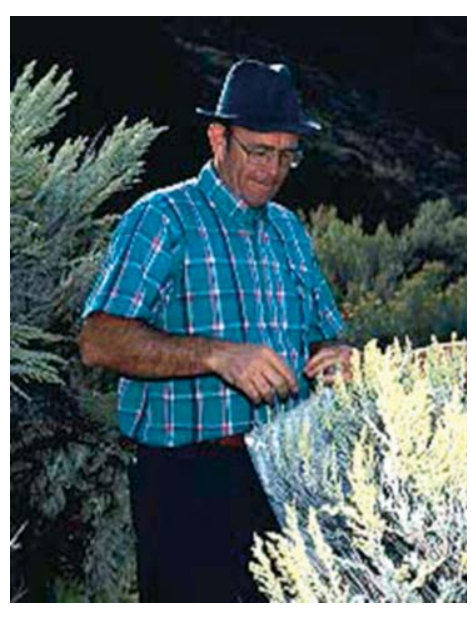

Durant McArthur scientist past or present. He is the world's expert on the sagebrush that is a critical habitat component for mule deer, sage grouse, and many other wildlife species.

In 2007, McArthur was designated leader of the Station's research for grassland, shrubland, and desert ecosystems. In that capacity he oversees arid land research from Canada to Mexico and from the Sierras to the Great Plains. In recent years he has overseen research in restoring damaged ecosystems in Utah and the Great Basin, and worked to find ways

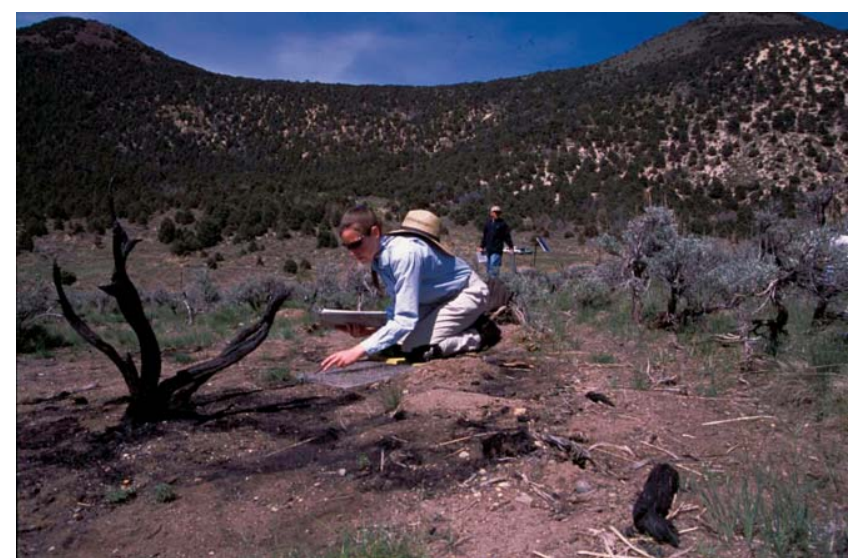

An unidentified technician in Nevada collecting data on cheatgrass germination for sagebrush/fire/cheatgrass dynamics.

to combat the invasion of cheatgrass that is degrading rangelands and critical wildlife habitat across the West.

Previous awards include the Utah Society of Range Management's Manager of the Year Award in 2004, Shrub Research Consortium Distinguished Service Award 2002, Eminent Science Publication Award 2000, Forest Service Distinguished Scientist Award 1996, International Society for Range Management Outstanding Achievement Award 1992, and Forest Service Superior Scientist Award 1990.

McArthur has raised a family and been very active in church and community affairs near his home in Orem. He grew up in Utah's Washington County and attended the University of Utah. He often rides his bike to work and plays pickup basketball at BYU. 